
Not for reproduction, distribution or commercial use.

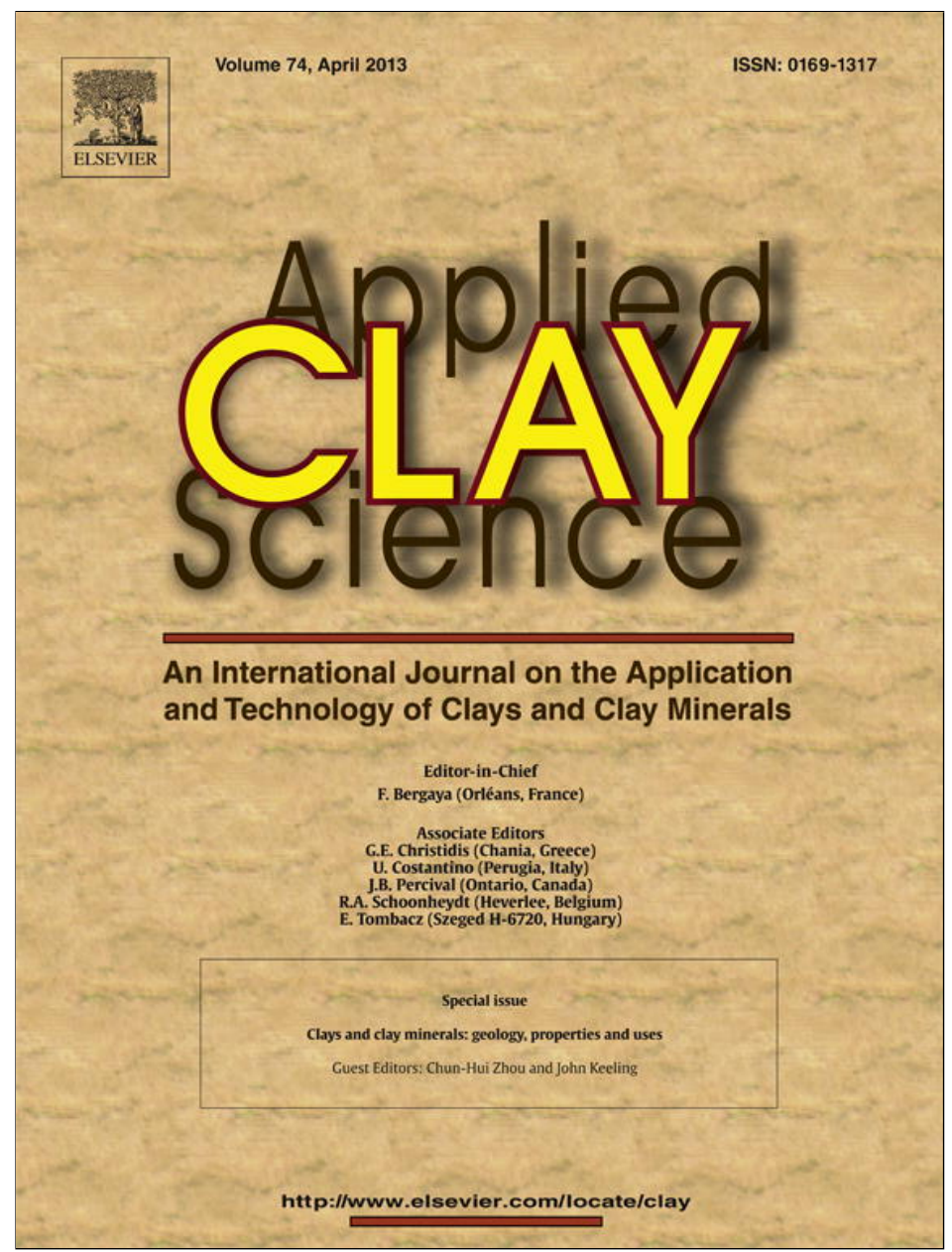

This article appeared in a journal published by Elsevier. The attached copy is furnished to the author for internal non-commercial research and education use, including for instruction at the authors institution and sharing with colleagues.

Other uses, including reproduction and distribution, or selling or licensing copies, or posting to personal, institutional or third party websites are prohibited.

In most cases authors are permitted to post their version of the article (e.g. in Word or Tex form) to their personal website or institutional repository. Authors requiring further information regarding Elsevier's archiving and manuscript policies are encouraged to visit: 
Research paper

\title{
Natural zeolite from Pacitan Indonesia, as catalyst support for transesterification of palm oil
}

\author{
Ricky Indra Kusuma, Johan Prabowo Hadinoto, Aning Ayucitra, Felycia Edi Soetaredjo, Suryadi Ismadji * \\ Department of Chemical Engineering, Widya Mandala Surabaya Catholic University, Kalijudan 37, Surabaya 60114, Indonesia
}

\section{A R T I C L E I N F O}

\section{Article history:}

Received 9 January 2012

Received in revised form 20 April 2012

Accepted 26 April 2012

Available online 12 July 2012

\section{Keywords:}

Biodiesel

Transesterification

Solid catalyst

Zeolite

Palm oil

\begin{abstract}
A B S T R A C T
The transesterification of palm oil to methyl esters (biodiesel) was studied using $\mathrm{KOH} /$ zeolite as solid heterogeneous catalysts. Various process variables such as $\mathrm{KOH}$ concentration and reaction time were studied in order to obtain maximum yield of biodiesel. A series of $\mathrm{KOH} /$ zeolite catalyst was prepared by impregnation of zeolite from Pacitan with potassium hydroxide in a various concentration $(25 \mathrm{~g} \mathrm{KOH}$ in $100 \mathrm{~mL}$ of distilled water; $50 \mathrm{~g} \mathrm{KOH}$ in $100 \mathrm{~mL}$ of distilled water; $75 \mathrm{~g}$ in $100 \mathrm{~mL}$ of distilled water; and $100 \mathrm{~g}$ in $100 \mathrm{~mL}$ of distilled water). The weight ratios between zeolite and $\mathrm{KOH}$ solution were 1:4. Transesterification was carried out at various reaction times ( 1 to $4 \mathrm{~h}$ ). The impregnation of zeolite with $\mathrm{KOH}$ concentration of $100 \mathrm{~g} / 100 \mathrm{~mL}$ gave maximum yield of biodiesel. The natural zeolite, catalyst, and spent catalysts were characterised by using several techniques such as XRD, EDX, and SEM.
\end{abstract}

(C) 2012 Elsevier B.V. All rights reserved.

\section{Introduction}

Petroleum-based fuel is still the main source of energy used by all countries in the world. Extensive uses of this un-renewable fuel cause the depletion of petroleum-based fuel sources. Various kinds of alternative energy sources have been explored (Zhou et al., 2011), and one of them is biodiesel. Biodiesel has been considered as an alternative source of petroleum-based fuel due to its similarity to petroleum-based diesel (Noiroj et al., 2009). Chemically, biodiesel is a mixture of methyl esters with long-chain fatty acids that can be produced through transesterification process of vegetable oils and animal fats (Leung et al., 2010). This process is usually carried out in the presence of a homogeneous base or acid catalysts in order to reduce the reaction temperature and to control the product selectivity (Benjapornkulaphong et al., 2009). In the homogeneous method, the reactants, catalyst, and FAME are all in the liquid phase, which is difficult to separate the catalyst from the after-reaction product (Kansedo et al., 2009). On the other hand, homogeneous base catalysts such as sodium hydroxide cannot be recovered or regenerated after the reaction and also produce toxic wastewater (Soetaredjo et al., 2011). Solid catalysts are a new choice to replace the liquid homogeneous catalyst due to its advantages such as less corrosive, easier to handle and separate, reusable and generating less amount of toxic wastes (Helwani et al., 2009).

\footnotetext{
* Corresponding author. Tel.: + 62 313891264; fax: + 62313891267 E-mail address: suryadiismadji@yahoo.com (S. Ismadji).
}

Recently, there has been increasing development of heterogeneous catalyst. Solid catalysts that have been studied and used for transesterification of vegetable oils including alkali and alkali earth metal supported on $\mathrm{Al}_{2} \mathrm{O}_{3}$ (Benjapornkulaphong et al., 2009; Noiroj et al., 2009), alum (Aderemi and Hameed, 2009), $\mathrm{K}_{2} \mathrm{CO}_{3}$ supported on alumina/silica (Lukic et al., 2009), calcium oxide (Boey et al., 2009), calcium-zinc mixed oxide (Ngamcharussrivichai et al., 2008), quick lime bit (Kouzu et al., 2009), mesoporous molecular sieves MCM-41 (Carmo et al., 2009), and $\mathrm{KOH}$ supported on bentonite (Soetaredjo et al., 2011), etc. However, the drawback of using solid materials as catalyst for biodiesel production, especially the synthesized ones, is on its price. To reduce the cost of production, the solid catalyst should be low in price, and available in large quantity.

Zeolite is a crystalline aluminosilicate with a three-dimensional framework structure that forms uniform pore size (Cejka et al., 2007). Because of its important chemical properties, this material has been applied in many industrial application such as selective absorbent, ion-exchange resin, and high activity catalyst (Xia et al., 2011; Zhang et al., 2010; Zhou, 2010, 2011). Various kinds of solid materials as mentioned in previous paragraph have been used as heterogeneous catalyst or catalyst supports in biodiesel production, but study about the utilization of natural clay materials such as zeolite as catalyst or catalyst support for biodiesel is still scarce.

The present work was focused in modification of natural zeolitesupported $\mathrm{KOH}$ prepared through impregnation method as catalyst for transesterification of palm oil. In this study, we used natural zeolite from Pacitan (East Java, Indonesia). To the best of our knowledge, there is no information available about the utilization of natural zeolite as catalyst or catalyst support for biodiesel production. In the present 
study, the zeolite was used as catalyst support; the effects of $\mathrm{KOH}$ loading and transesterification conditions on the yield of biodiesel were also studied.

\section{Materials and methods}

\subsection{Materials}

Natural zeolite used in this study was obtained from Pacitan, East Java, Indonesia. Prior to use, natural zeolite was crushed using a JANKE \& KUNKEL micro hammer mill to obtain zeolite with particle size of $170 / 240$ mesh. Subsequently, the zeolite was treated with $30 \%$ of hydrogen peroxide solution to remove the organic impurities. Excess hydrogen peroxide solution was removed by gently heating in a water bath, and the solution was separated from the zeolite. Subsequently, the purified zeolite was repeatedly washed and dispersed in distilled water. After the water have been separated from zeolite, the purified zeolite was then dried in an oven at $110^{\circ} \mathrm{C}$ for $24 \mathrm{~h}$ to remove moisture content from its structure. The dried zeolite was finally crushed in a micro hammer mill to obtain powder zeolite with particle size of 170 / 240 mesh.

For transesterification study, the refined palm oil (Bimoli) was purchased from local market, while analytical grade methanol, potassium hydroxide, and n-hexane were obtained from Merck, Darmstadt, Germany. The standard fatty acid methyl ester for FAME analysis was purchased from Sigma Aldrich (Singapore).

\subsection{Catalyst preparation}

A series of zeolite catalysts was prepared by impregnation with $\mathrm{KOH}$ at different $\mathrm{KOH}$ concentrations. A brief procedure of catalyst preparation is as follows: a known amount of $\mathrm{KOH}(25,50,75$, and $100 \mathrm{~g}$ ) was added into $100 \mathrm{~mL}$ distilled water, followed by the addition of zeolite powder into the solution. The weight ratio between zeolite and $\mathrm{KOH}$ solution was 1:4. Afterwards, the mixture was removed to three-neck flask equipped with reflux condenser. The mixture of zeolite and $\mathrm{KOH}$ solution was stirred at $60^{\circ} \mathrm{C}$ for $24 \mathrm{~h}$. Subsequently, zeolite and $\mathrm{KOH}$ solution was separated by filtration using a vacuum filter system. The zeolite catalyst was then ovendried at $110{ }^{\circ} \mathrm{C}$ for $24 \mathrm{~h}$, and calcined in a furnace at $450{ }^{\circ} \mathrm{C}$ for $4 \mathrm{~h}$.

\subsection{Material and catalyst characterization}

Natural zeolite and catalysts were characterized using several methods such as X-ray Diffraction analysis, Energy-Dispersive X-ray (EDX) spectrometry, and scanning electron microscopy (SEM). The X-ray Diffraction analysis was conducted using a Philips X-pert Powder Analytical diffractometer, and as a source for $\mathrm{CuK}_{\alpha}$ radiation (1.54056 $\AA$ ) a $2.2 \mathrm{~kW} \mathrm{Cu}$ anode was used. The XRD pattern was obtained at operating condition $40 \mathrm{kV}$ and $40 \mathrm{~mA}$ with $2 \theta$ measurements between the ranges of $5^{\circ}$ to $90^{\circ}$.

Since potassium plays an important role in transesterification of palm oil into biodiesel, the potassium content both in raw zeolite and catalyst was determined by an Energy-dispersive X-ray (EDX) spectrometry (Shimadzu EDX-720/800HS). EDX was used in conjunction with scanning electron microscopy (SEM). The EDX technique detects X-rays emitted from the sample during bombardment by the SEM's electron beam; electrons are ejected from the atoms comprising the sample's surface. The resulting electron vacancies are filled by electrons from a higher state, and an X-ray is emitted to balance the energy difference between the two electrons' states. The EDS X-ray detector measures the relative abundance of emitted X-rays versus their energy. The surface topography of zeolite and catalyst was examined using Cambridge scanning electron microscope (S-360) at an accelerating voltage of $20 \mathrm{kV}$. Zeolite and catalyst samples were mounted on a double-sided tape attached to a metal stub and sputtered with gold under argon vacuum in order to make the sample conductive.

\subsection{Transesterification}

Transesterification of palm oil into biodiesel was carried out in a $500 \mathrm{~mL}$ three-neck flask equipped with reflux condenser, temperature indicator, and controlled water bath heater. The reaction procedure is as follows: mixture of catalyst and methanol was heated to $60{ }^{\circ} \mathrm{C}$ under continuous stirring at $500 \mathrm{rpm}$. Subsequently, $125 \mathrm{~mL}$ of palm oil was added to the reactor. Molar ratio of palm oil and methanol used in this study was 1:7, and the amount of catalyst used was $3 \%$ weight of palm oil. Transesterification experiment was carried out at reaction time of 1 to $4 \mathrm{~h}$. At the end of the reaction, the reactor was cooled to room temperature and the catalyst was separated from product mixture using vacuum filter.

The biodiesel product was separated from glycerol using funnel separator. Subsequently, the excess methanol was removed from the biodiesel product using vacuum rotary evaporator. Biodiesel product was then repeatedly washed using warm distilled water $\left(60^{\circ} \mathrm{C}\right)$. The fatty acid methyl ester or FAME layer (upper layer) was separated from water layer (bottom layer) using funnel separator. Some amount of sodium sulfate was added to the biodiesel product to remove residual water from the fatty acid methyl ester.

\subsection{Determination and characterization of FAME contents}

FAME content in biodiesel product was determined by gas chromatography analysis (GC Shimadzu 2014). The GC was equipped with a DB-Wax capillary column $(30 \mathrm{~m} \times 0.25 \mathrm{~mm}$ i.d. $\times 0.1 \mu \mathrm{m}$ film thickness, Agilent JW Scientific) and flame ionization detector (FID). Helium was employed as carrier gas at $40 \mathrm{~cm} / \mathrm{s}$. The injector temperature was $250{ }^{\circ} \mathrm{C}$ at splitless condition. The FID was set at $300{ }^{\circ} \mathrm{C}$. The initial oven temperature was set at $50{ }^{\circ} \mathrm{C}$ with equilibration time of $3 \mathrm{~min}$. After isothermal period, oven temperature was increased to $250{ }^{\circ} \mathrm{C}$ at heating rate of $10^{\circ} \mathrm{C} / \mathrm{min}$ and held for $8 \mathrm{~min}$. Peaks of methyl esters were identified by comparing them with the reference standard. The yield of biodiesel was determined by the following equation:

$$
\begin{aligned}
\text { Yield }(\%)= & (\text { weight of biodiesel } \times \% \text { FAME in sample }) \\
& /(\text { weight of palm oil }) \times 100 \%
\end{aligned}
$$

where FAME is fatty acid methyl esters. Several physical properties of biodiesel product were also determined according to ASTM standard and the results were compared with the Indonesia National Standard for biodiesel. The kinematic viscosity was determined based on ASTM D445-10, 2010, while ASTM standard D.93, 2010 was employed for the determination of flash point. Cetane index and density/specific gravity of biodiesel wereanalyzed according to ASTM D.613, 2010, and ASTM D.1298, 2005, respectively.

Table 1

Fatty acid composition of palm oil.

\begin{tabular}{lr}
\hline Fatty acid & $\%$ \\
\hline Lauric acid (C12:0) & 0.8 \\
Myristic acid (C14:0) & 1.2 \\
Palmitic acid (C16:0) & 42.9 \\
Palmitoleic acid (C16:1) & 0.2 \\
Stearic acid (C18:0) & 4.7 \\
Oleic acid (C18:1) & 40.4 \\
Linoleic acid (C18:2) & 9.4 \\
Linolenaic acid (C18:3) & 0.1 \\
Arachinoeic acid (C20:0) & 0.3 \\
\hline
\end{tabular}




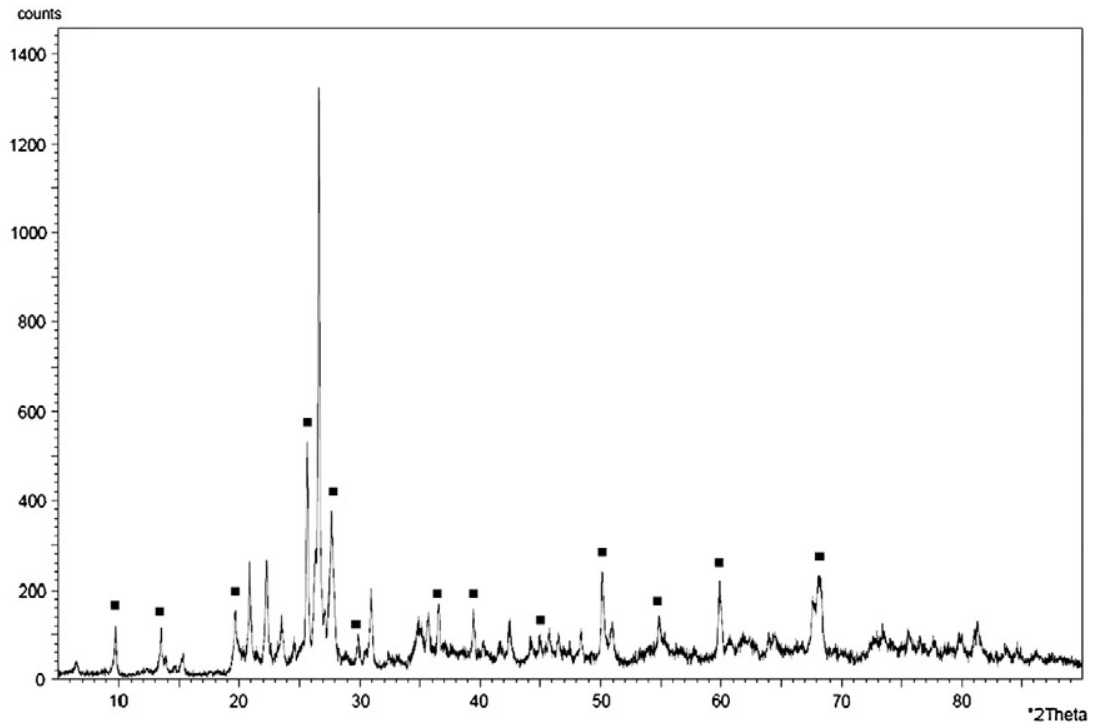

Fig. 1. The XRD pattern of raw zeolite.

\section{Results and discussion}

\subsection{Characteristic of palm oil}

The physical and chemical properties of palm oil were determined using standard test methods. These include density (ASTM D1298, 2005), kinematic viscosity (ASTM D445-10, 2010), free fatty acid content, and flash point (ASTM D93, 2010). The results were as follows: the density at $25^{\circ} \mathrm{C}$ was $0.9016 \mathrm{~g} / \mathrm{cm}^{3}$, kinematic viscosity at $23.4^{\circ} \mathrm{C}$ was $70.9 \mathrm{cSt}$, free fatty acid and flash point were $0.02 \%$ and $220^{\circ} \mathrm{C}$, respectively. The chemical composition of palm oil used in this study was analyzed using gas chromatography (GC Shimadzu 2014) and the results are summarized in Table 1.

\subsection{Catalyst characterisation}

\subsubsection{X-ray diffraction (XRD)}

X-ray diffraction analysis was performed to identify the internal structure, bulk phase, and crystallinity of the catalyst. The XRD pattern of raw zeolite is shown in Fig. 1. Fig. 1 shows the typical diffraction peaks of zeolite at Bragg angle $(2 \theta)=12.4^{\circ} ; 19.4^{\circ} ; 29,9^{\circ} ; 37.1^{\circ} ; 45^{\circ}$; $56^{\circ}$; and $60.6^{\circ}$. The pattern also indicates that the raw zeolite used in this study was classified into mordenite.

Fig. 2 depicts the XRD pattern of modified zeolite/catalyst. A new phase of $\mathrm{K}_{2} \mathrm{O}$ can be observed at Bragg angle $(2 \theta)=31^{\circ} ; 39^{\circ} ; 51^{\circ} ; 55^{\circ}$; and $62^{\circ}$. During calcinations, molecules of potassium hydroxide in zeolite surface and matrix were transformed into $\mathrm{K}_{2} \mathrm{O}$. Potassium oxide $\left(\mathrm{K}_{2} \mathrm{O}\right)$ is believed to play an important role during the transesterification of oil into fatty acid methyl esters since it has high catalytic activity.

\subsubsection{Energy-dispersive X-ray spectrometry (EDX)}

Potassium content in raw zeolite, modified zeolite/catalyst, and spent catalyst (after three reaction cycle) was determined using Energy-dispersive X-ray (EDX) spectrometry, and the results were $3.01 \%$ (weight) for raw zeolite, $45.34 \%$ and $43.80 \%$ for fresh catalyst (modified zeolite) and spent catalyst, respectively. The result showed that the potassium content on the modified zeolite increased after the impregnation with $\mathrm{KOH}$. This indicates that potassium molecules

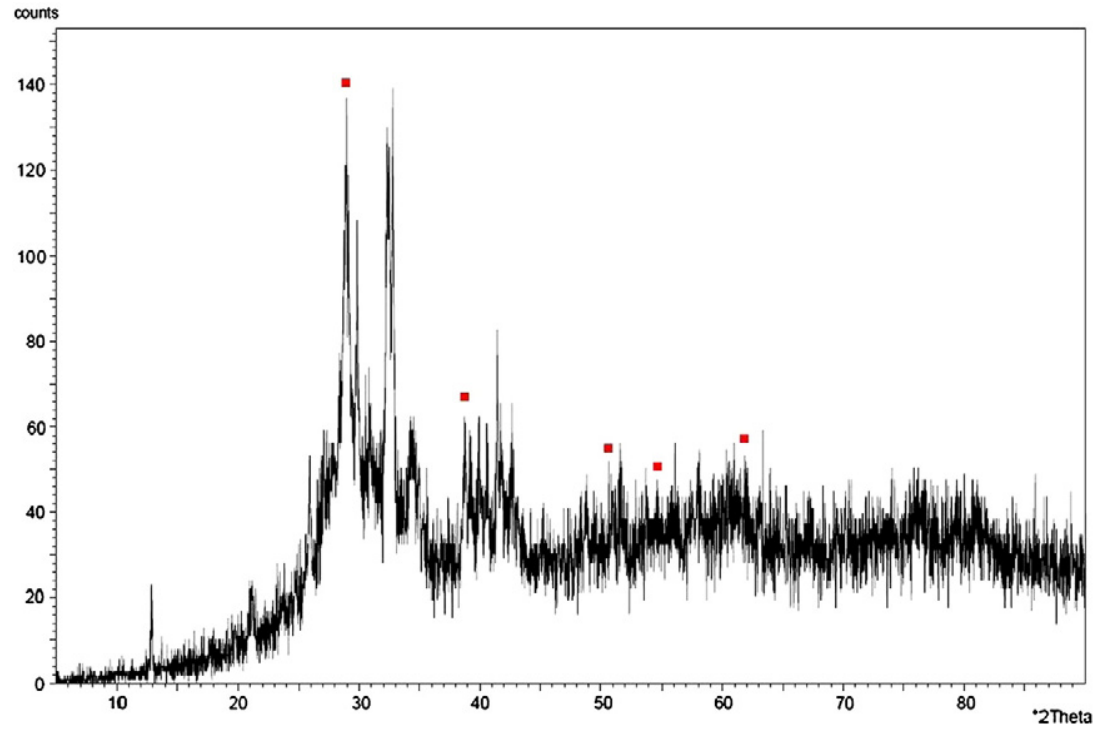

Fig. 2. XRD pattern of catalyst. 
were attached or incorporated into zeolite structure or matrix during the impregnation process.

Reusability and stability of catalyst for biodiesel synthesis are very important for the industrial application. Potassium molecules should strongly attach on the structure of zeolite to make the catalyst stable. In order to examine the stability of catalyst, three consecutive reaction cycles using the same catalyst were conducted. After three reaction cycle test, the potassium content was also analyzed using EDX, and it was found that the potassium content in catalyst

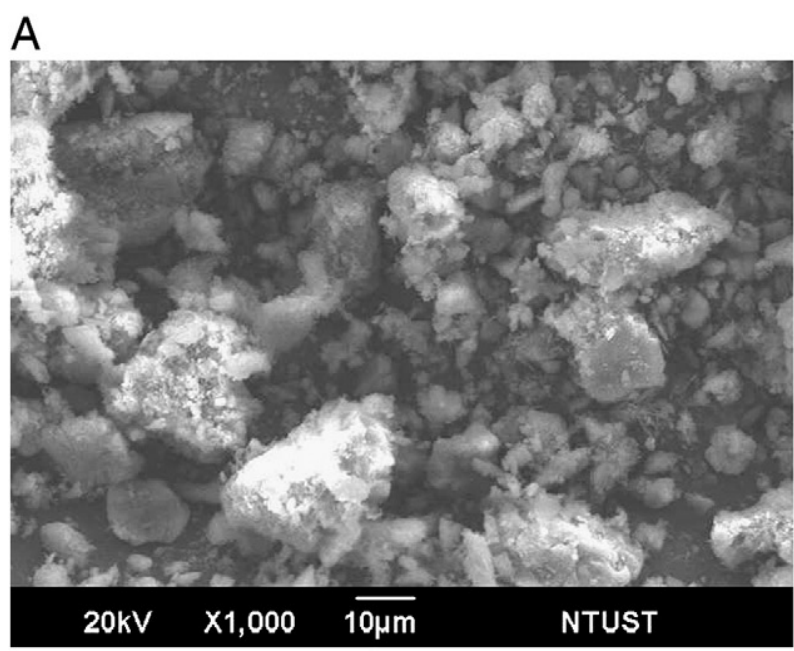

B
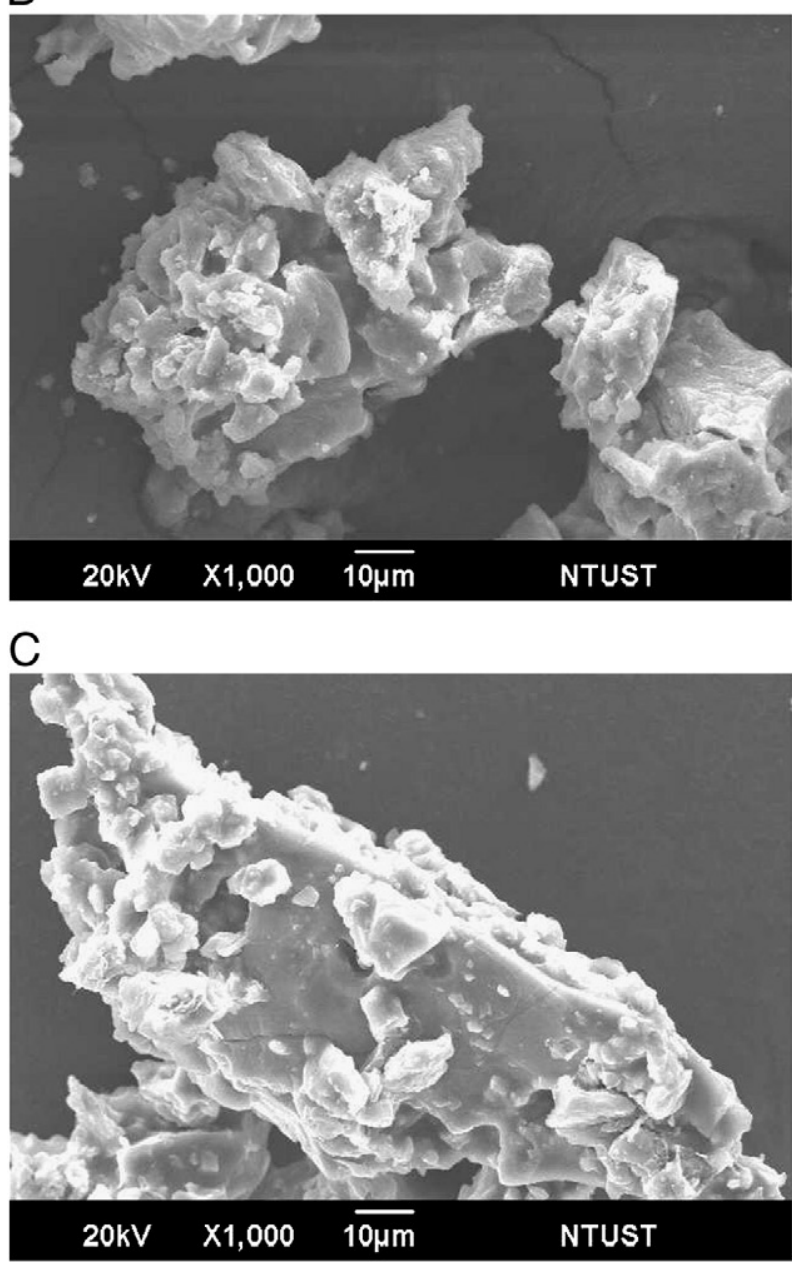

Fig. 3. SEM micrographs of (A) raw zeolite, (B) catalyst, and (C) spent catalyst after three reaction cycles.

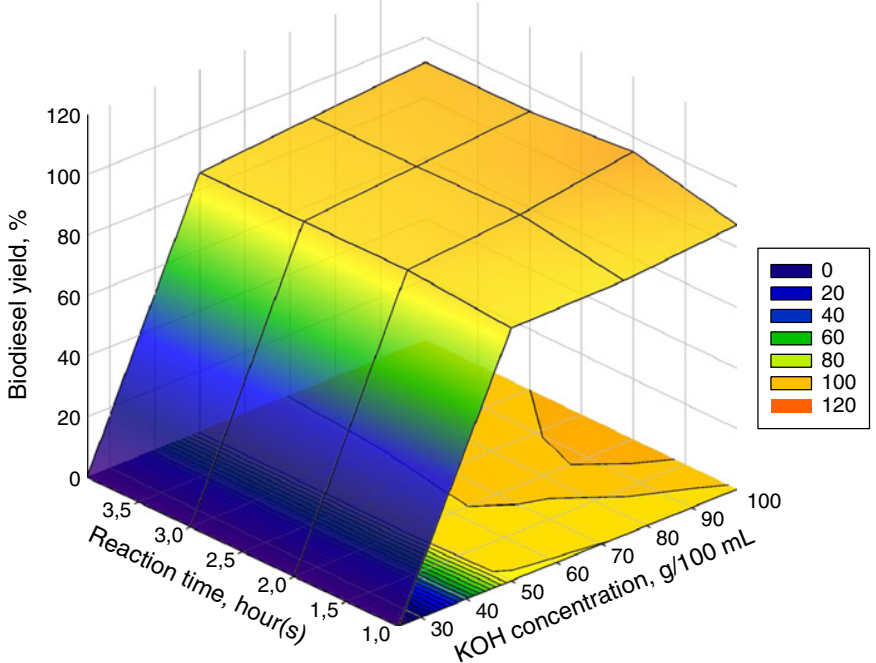

Fig. 4. The effect of catalyst loading and reaction time on the yield of biodiesel (reaction time between 1 and $4 \mathrm{~h}$, amount of catalyst used was 3\%, oil to methanol ratio 1:7, and reaction temperature $60^{\circ} \mathrm{C}, \mathrm{KOH}$ concentration for zeolite impregnation $25-100 \mathrm{~g} / 100 \mathrm{~mL}$ ).

decreased from $45.34 \%$ to $43.80 \%$. This evidence indicates that the stability of catalyst is relatively good because only around $3.40 \%$ of the potassium content was leached during three reaction cycles.

\subsubsection{Scanning electron microscopy (SEM)}

The surface topography of raw zeolite, modified zeolite/catalyst, and spent catalyst (after three reaction cycles) was analyzed using scanning electron microscopy (SEM). The macrostructure of raw zeolite and its modified form remain intact after the calcination process, confirming the high thermal stability of zeolite (Fig. 3A and B). The surface topography of used catalyst also did not change significantly after reused for three reaction cycles (Fig. 3C).

\subsection{Transesterification reaction}

The transesterification of palm oil using $\mathrm{KOH} /$ zeolite as catalyst was performed under following conditions: catalyst amount 3\%, ratio of palm oil to methanol $1: 7$, reaction temperature $60^{\circ} \mathrm{C}$, and stirring speed $700 \mathrm{rpm}$.

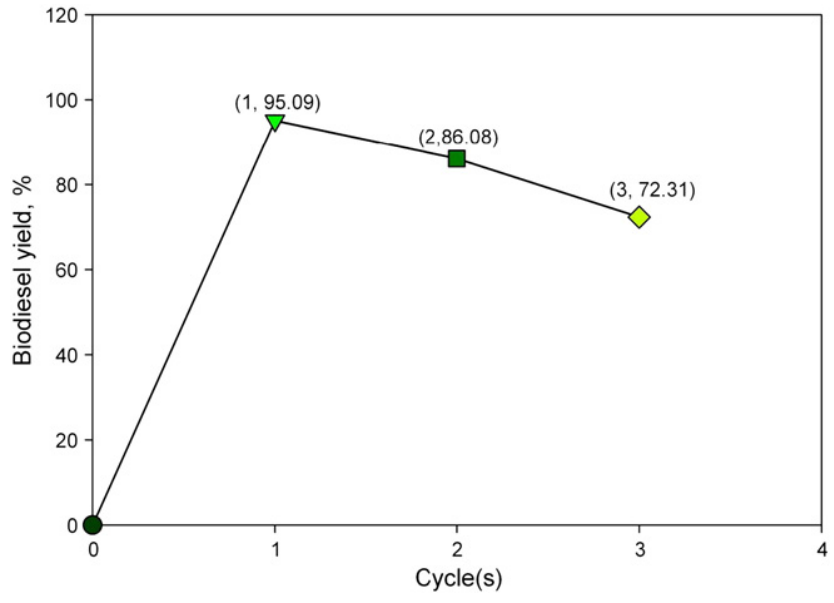

Fig. 5. Multiple cycle test of catalyst deactivation (impregnation with $100 \mathrm{~g} / 100 \mathrm{~mL}$ $\mathrm{KOH}$, reaction time $2 \mathrm{~h}$, reaction temperature $60^{\circ} \mathrm{C}$, ratio of palm oil and methanol was $1: 7$, and $3 \%$ of catalyst amount). 
Table 2

Comparison of the properties of biodiesel produced from palm oil with $\mathrm{KOH} /$ zeolite catalyst with the Indonesia National Standard (SNI-04-7182-2006).

\begin{tabular}{lcl}
\hline Properties & Biodiesel produced & SNI \\
\hline Density at $15{ }^{\circ} \mathrm{C}, \mathrm{g} / \mathrm{mL}$ & $0.884 \pm 0.00343$ & $0.86-0.90$ \\
Kinematic viscosity at $40{ }^{\circ} \mathrm{C}, \mathrm{cSt}$ & $5.121 \pm 0.221$ & $1.9-6.0$ \\
Flash point, ${ }^{\circ} \mathrm{C}$ & $170.417 \pm 0.434$ & Min 65 \\
Cetane number & $58.500 \pm 1.525$ & $>45$ \\
\hline
\end{tabular}

\subsubsection{Effect of $\mathrm{KOH}$ loading on biodiesel yield}

To study the effect of potassium hydroxide $(\mathrm{KOH})$ loading on the yield of biodiesel, a series of $\mathrm{KOH} /$ zeolite catalyst was prepared by impregnated zeolite with different concentration of $\mathrm{KOH}$. The effect of $\mathrm{KOH}$ loading on the yield of biodiesel is shown in Fig. 4. This figure reveals that the yield of biodiesel increased with the increase of $\mathrm{KOH}$ loading. With the increased of $\mathrm{KOH}$ loading, the amount of $\mathrm{KOH}$ entering the structure of zeolite also increased. During the calcination process, $\mathrm{KOH}$ was converted into potassium oxide $\left(\mathrm{K}_{2} \mathrm{O}\right)$ as shown in XRD pattern. As reported by Noiroj et al. (2009) and Soetaredjo et al. (2011), $\mathrm{K}_{2} \mathrm{O}$ has a high catalytic performance for transesterification process. Along with the increased of $\mathrm{KOH}$ amount in the structure of zeolite, the formation of $\mathrm{K}_{2} \mathrm{O}$ which acts as active sites for transesterification process was also increased, thus increased the yield of biodiesel.

\subsubsection{Effect of reaction time on biodiesel yield}

The effect of reaction time on the transesterification of palm oil into biodiesel was studied at reaction time between 1 and $4 \mathrm{~h}$. The transesterification reaction consists of three step reactions to convert triglyceride to final product, methyl ester and glycerol. In the first step, the triglycerides react with one molecule of alcohol, produce diglycerides and one molecule of ester. The molecule of diglycerides then reacts with another molecule of alcohol to produce monoglyceride and one molecule of ester. Finally, the reaction between monoglyceride and methanol produces methyl ester and glycerol. Therefore, it is important to select a proper transesterification time to ensure the completion of the reaction, especially if heterogeneous catalyst is used.

The effect of reaction time on the biodiesel produced is also depicted in Fig. 4. In the first hour of reaction, only some triglycerides were completely converted into fatty acid methyl ester (biodiesel). Furthermore, the rate of reaction was relatively slow in the first hour due to the problem of mixing and dispersion between palm oil and methanol (Freedman et al., 1986). With increasing of reaction time the amount of biodiesel produced also increased, and after $2 \mathrm{~h}$ of reaction time, the yield of biodiesel was essentially constant with time. The equilibrium condition of transesterification reaction of palm oil with methanol has been reached after $2 \mathrm{~h}$.

\subsubsection{Catalyst stability and reusability}

The reusability and stability of heterogeneous catalyst are the most important criteria in the selection of appropriate catalyst for industrial application. Noiroj et al. (2009) mentioned that in heterogeneous catalyst application for biodiesel preparation, it is important to ensure that the active species are not leached from the solid support of the catalyst during the process. In this study, the reusability of $\mathrm{KOH} / z e o l i t e$ catalyst was determined by carrying out three transesterification reaction cycles. The following reaction conditions were applied: reaction time of $2 \mathrm{~h}$, palm oil to methanol molar ratio was $1: 7$, catalyst amount of $3 \%$ weight of palm oil, reaction temperature of $60^{\circ} \mathrm{C}$, and stirring speed was at $500 \mathrm{rpm}$.

(1)<smiles>[R]OC(=O)OCC(COC([R4])=O)O[R]([H])=O</smiles>

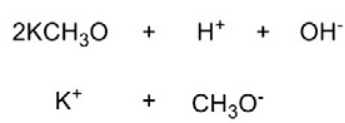<smiles>[R]OC(C)OCC(COC([R])=O)OC([2H])([2H])[O-]</smiles><smiles></smiles><smiles>C=CCCC</smiles><smiles>[R]OC(=O)OCC(C[O-])OC(C)=O</smiles><smiles>[R]OC(=O)OCC(C[O-])OC([R])=O</smiles><smiles>C=CC</smiles><smiles>[R]OC(=O)OCC(CO)OC([R])=O</smiles>

Diglyceride

(4b)<smiles>[R]OC(=O)OCC(C[O-])OC([R])=O</smiles><smiles>C=CCC</smiles> 
For fresh catalyst (at $\mathrm{KOH}$ concentration of $100 \mathrm{~g} / 100 \mathrm{~mL}$ ) the maximum conversion was $95.09 \%$ as shown in Fig. 5. For subsequent reaction, the biodiesel yield was decreased to $86.08 \%$, and for the third cycle the yield of biodiesel was just only $72.31 \%$ (Fig. 5). The decrease of biodiesel yield occurred because some of the active species in $\mathrm{KOH} /$ zeolite catalyst were leached or deactivated during transesterification reaction of palm oil with methanol. This phenomenon was supported by the EDX result which indicated that the potassium content in catalyst decreased from $45.34 \%$ to $43.80 \%$.

\subsection{Biodiesel characterisation}

The physical and chemical properties (density, kinematic viscosity, flash point, and cetane number) of biodiesel produced by transesterification of palm oil with methanol using $\mathrm{KOH} /$ zeolite solid catalyst were determined by standard analysis as mentioned in Section 3.1 and the results were compared with the Indonesia National Standard for biodiesel, as shown in Table 2.

Since it affects the performance of injector, viscosity is the most important property of biodiesels; particularly at low temperatures when an increase in viscosity affects the fluidity of the fuel. The lower the viscosity of the biodiesel, the easier it is to pump and atomize and achieve finer droplets (Islam and Beg, 2004). The minimum value of flash point is required for safety and handling of the fuel. It is used to characterize the fire hazards of liquids. Since the flash point of biodiesel produced from this study is high (more than $60.5^{\circ} \mathrm{C}$ ), therefore, this fuel is safe for handling and storage for some period of time. With a high value of flash point, this biodiesel is considered as combustible.

Cetane number relates to the combustion quality of diesel fuel during compression ignition and also the ignition quality of diesel fuels. The cetane index of biodiesel obtained in this study is higher than conventional diesel fuel (45 to 55). This is due to the major contents of this fuel which are the methyl palmitate and methyl stearate which have the cetane index of 59.3 and 85.9, respectively (Rashid et al., 2011).

\subsection{Proposed reaction mechanism}

The transesterification reaction mechanism for biodiesel production using $\mathrm{KOH} /$ zeolite as catalysis is shown in Fig. 6. The mechanism is as follows: the first step of reaction is the formation of methoxide ion $\left(\mathrm{CH}_{3} \mathrm{O}^{-}\right)$from the reaction between the active site of catalyst $\left(\mathrm{K}_{2} \mathrm{O}\right)$ with methanol. This methoxide ion is a strong base which has high catalytic activity in the transesterification reaction (Gryglewicz, 1999).

In the next step, the reactive methoxide ion attacks the carbonyl carbon atom of triglyceride leading to the formation of tetrahedral intermediate. Further rearrangement of tetrahedral intermediate produced one molecule of methyl ester and diglyceride anion. The reconstruction of diglyceride molecule began with the reaction with $\mathrm{H}^{+}$from the catalyst. On the other hand, the diglyceride anion may also react with methanol and generate reactive methoxide ion (Ma and Hanna, 1999). The catalytic reaction was then followed by the reaction between diglyceride and other methoxide ion to produce monoglyceride molecule and one molecule of methyl ester. Finally, carbonyl carbon atom of monoglyceride was attacked by methoxide ion producing one molecule of methyl ester and one molecule of glycerol.

\section{Conclusion}

Natural zeolite from Pacitan, East Java, Indonesia, was employed as catalyst support for biodiesel production. The catalyst was prepared by impregnating the zeolite with potassium hydroxide solution. The $\mathrm{KOH}$ loaded zeolite was then calcined at $450{ }^{\circ} \mathrm{C}$. During calcination, the $\mathrm{KOH}$ was converted into $\mathrm{K}_{2} \mathrm{O}$, which was believed to be the active site during the transesterification reaction. The maximum yield of biodiesel was $95.09 \%$, and obtained at following operation condition: impregnation with $100 \mathrm{~g} / 100 \mathrm{~mL} \mathrm{KOH}$, reaction time of $2 \mathrm{~h}$, reaction temperature of $60{ }^{\circ} \mathrm{C}$ and ratio of palm oil and methanol was $1: 7$, and 3\% weight of catalyst amount. During three cycles of transesterification reaction, $3.40 \%$ of active site of catalyst was leached from zeolite structure.

\section{Acknowledgments}

The authors would like to acknowledge the support of the Department of Chemical Engineering, Widya Mandala Catholic University Surabaya and also to the Department of Chemical Engineering, National Taiwan University of Science and Technology for EDX and SEM analysis.

\section{References}

Aderemi, B.O., Hameed, B.H., 2009. Alum as a heterogeneous catalyst for the transesterification of palm oil. Applied Catalysis A: General 370, 54-58.

Benjapornkulaphong, S., Ngamcharussrivichai, C., Bunyakiat, K., 2009. $\mathrm{Al}_{2} \mathrm{O}_{3}$-supported alkali and alkali earth metal oxides for transesterification of palm kernel oil and coconut oil. Chemical Engineering Journal 145, 468-474.

Boey, P.-L. Maniam, G.P. Hamid, S.A. 2009. Biodiesel production via transesterification of palm olein using waste mud crab (Scylla serrata) shell as a heterogeneous catalyst. Bioresource Technology 100, 6362-6368.

Carmo Jr., A.C., de Souza, L.K.C., da Costa, C.E.F., Longo, E., Zamian, J.R., da Rocha Filho, G.N., 2009. Production of biodiesel by esterification of palmitic acid over mesoporous aluminosilicate Al-MCM-41. Fuel 88, 461-468.

Cejka, J., Bekkum, H.V., Corma, A., 2007. Introduction to Zeolite Science and Practice. Elsevier, Oxford.

Freedman, B., Butterfield, R.O., Pryde, E.H., 1986. Transesterification kinetics of soybean oil. Journal of the American Oil Chemists' Society 63, 1375-1380.

Gryglewicz, S., 1999. Rapeseed oil methyl esters preparation using heterogeneous catalysts. Bioresource Technology 70, 249-253.

Helwani, Z., Othman, M.R., Aziz, N., Kim, J., Fernando, W.J.N., 2009. Solid heterogeneous catalysts for transesterification of triglycerides with methanol: a review. Applied Catalysis A: General 363,1-10.

Islam, M.N., Beg, M.R.A., 2004. The fuel properties of pyrolysis liquid derived from urban solid wastes in Bangladesh. Bioresource Technology 92, 181-186.

Kansedo, J., Lee, K.T., Bhatia, S., 2009. Biodiesel production from palm oil via heterogeneous transesterification. Biomass and Bioenergy 33, 271-276.

Kouzu, M., Hidaka, J.-s., Komichi, Y., Nakano, H., Yamamoto, M., 2009. A process to transesterify vegetable oil with methanol in the presence of quick lime bit functioning as solid base catalyst. Fuel 88, 1983-1990.

Leung, D.Y.C., Wu, X., Leung, M.K.H., 2010. A review on biodiesel production using catalyzed transesterification. Applied Energy 87, 1083-1095.

Lukic, I., Krstic, J., Jovanovic, D., Skala, D., 2009. Alumina/silica supported $\mathrm{K}_{2} \mathrm{CO}_{3}$ as a catalyst for biodiesel synthesis from sunflower oil. Bioresource Technology 100 4690-4696.

Ma, F., Hanna, M.A., 1999. Biodiesel production: a review. Bioresource Technology 70, $1-15$

Ngamcharussrivichai, C., Totarat, P., Bunyakiat, K., 2008. Ca and Zn mixed oxide as a heterogeneous base catalyst for transesterification of palm kernel oil. Applied Catalysis A: General 341, 77-85.

Noiroj, K., Intarapong, P., Luengnaruemitchai, A., Jai-In, S., 2009. A comparative study of $\mathrm{KOH} / \mathrm{Al} 2 \mathrm{O} 3$ and $\mathrm{KOH} / \mathrm{NaY}$ catalysts for biodiesel production via transesterification from palm oil. Renewable Energy 34, 1145-1150.

Rashid, U., Anwar, F., Knothe, G., 2011. Biodiesel from Milo (Thespesia populnea L.) seed oil. Biomass and Bioenergy 35, 4034-4039.

SNI, 2006. Standard of Biodiesel. SNI-04-7182-2006. Standar Nasional Indonesia, Jakarta.

Soetaredjo, F.E., Ayucitra, A., Ismadji, S., Maukar, A.L., 2011. KOH/bentonite catalysts for transesterification of palm oil to biodiesel. Applied Clay Science 53, 341-346.

Xia, H.S., Zhou, C.H., Tong, D.S., Yu, W.H., Liu, S.M., 2011. Preparation and catalysis in epoxidation of allyl chloride of zeolitic titanosilicate-1/smectitic clay minerals. Applied Clay Science 53 (2), 279-287.

Zhang, D., Zhou, C.H., Lin, C.X., Tong, D.S., Yu, W.H., 2010. Synthesis of clay minerals. Applied Clay Science 50,1-11.

Zhou, C.H., 2010. Emerging trends and challenges in synthetic clay-based materials and layered double hydroxides. Applied Clay Science 48, 1-4.

Zhou, C.H., 2011. An overview on strategies towards clay-based designer catalysts for green and sustainable catalysis. Applied Clay Science 53 (2), 97-105.

Zhou, C.H., Xia, X., Lin, C.X., Tong, D.S., Beltramini, J., 2011. Catalytic conversion of lignocellulosic biomass to fine chemicals and fuels. Chemical Society Reviews 40 5588-5617. 